\title{
Perineal rhabdomyosarcoma in a newborn child: pathological and biochemical studies with emphasis on contractile proteins
}

\author{
HF HILDEBRAND, * I KRIVOSIC, $\dagger$ X GRANDIER-VAZEILLE, $\ddagger$ D TETAERT, \\ AND G BISERTE* \\ From the *Institut de Recherches sur le Cancer de Lille et Unité 124 de l'INSERM, Lille, France, \\ $\dagger$ Laboratoire d'Anatomie Pathologique de l'Université de Lille II, France, and $\ddagger$ Unité de Recherches sur les \\ Protéines (U 16 de l'INSERM), Lille, France
}

SUMMARY Histological and ultrastructural studies have been undertaken on a perineal rhabdomyosarcoma from a newborn child. The spontaneous tumour has the typical feature of mesenchymoma. The recurrent tumour, however, displays some rhabdopoietic characteristics.

The myosin of the recurrent tumour has been extracted and compared with human fetal myosin. These two myosins are identical in their synthetic filaments and their light-chain composition. Nevertheless, whereas the ATPase activity of fetal myosin can be stimulated considerably by increasing the $\mathrm{Ca}^{2+}$ concentration, that of tumoral myosin remains very low.

These results show that there are isoenzymes of myosins and there must be differences in the myosin heavy chains, particularly in the active sites. These findings are identical with those seen in experimental rhabdomyosarcoma.

Human rhabdomyosarcoma is considered to be a relatively rare tumour. Investigation of this tumour during the last 15 to 20 years has shown, however, that embryonic and alveolar rhabdomyosarcomas are the two soft tissue tumours seen most frequently in children. In childhood, rhabdomyosarcoma accounts for 12 to $56 \%$ of all soft tissue tumours. ${ }^{1-10}$ The tumours may appear at any age in childhood, but the majority are seen in infants from 3 to 4 years of age. ${ }^{9}$ In children aged 10 to 12 years, rhabdomyosarcomas are less common, but they occur more frequently in adolescents 15 to 18 years old. ${ }^{35}$ Rhabdomyosarcomas are exceptional in the newborn. The high incidence of this tumour in these reported series reflects the greater confidence with which the diagnosis can now be made. This is to a great extent the result of electron microscopy.

Normal myoblasts grown in vitro display mobility and contract. This is not so with rhabdomyoblasts grown in culture; ${ }^{11}$ although one of the most typical characteristics of the tumour is lack of contractility, ${ }^{11}$ little attention has been paid to their contractile proteins. ${ }^{12-14}$ In previous investigations, ${ }^{14} 15$ tumoral myosins isolated from $\mathrm{Ni}_{3} \mathrm{~S}_{2}$-induced rhabdomyosarcomas in rats and rabbits were analysed and

Received for publication 17 July 1979 compared with normal and fetal skeletal myosins. Tumoral myosin was found to be a new isoenzyme with oncofetal character. The present report deals with the study of myosin from a spontaneous human tumour and compares it to myosin from experimentally induced tumours.

\section{Case report}

The tumour was seen in a full-term newborn girl weighing $3 \mathrm{~kg}$ at birth. She was the first child, and the parents had no genetic abnormalities. A vulvoperineal tumour, $10 \mathrm{~cm}$ in diameter, was found at birth. The tumour pushed back the labia majora. In addition, the left tibia showed a focus of osteolysis. The tumour was excised on the fifth day of life. It was hard and vascularised and had a lobulated structure. During surgery the bladder, vagina, and rectum were completely freed Irom the tumour which weighed $180 \mathrm{~g}$. The infant died aged 3 months with a local recurrence of the same size as the primary tumour, which was excised immediately after death.

\section{Material and methods}

LIGHT MICROSCOPY

Portions of tissue were taken and fixed in Dubosc- 
Brasil's fluid and in formaldehyde. The fixed material was embedded in paraffin, and sections 5-8 $\mu \mathrm{m}$ thick were stained with haematoxylin and eosin, Masson's trichrome, Mallory's phosphotungstic acid haematoxylin, Wilder's reticulin, and Heidenhain's azan.

\section{ELECTRON MICROSCOPY}

The primary tumour was cut into serial sections which were fixed in formalin for 72 hours. Small pieces were then minced into $1 \mathrm{~mm}$ cubes and placed in $10 \%$ Millonig's buffered formalin. Small tissue portions (about $1 \mathrm{~mm}^{3}$ ) of the recurrent tumour were fixed for 1 hour in $5 \%$ glutaraldehyde in Millonig's buffer. The samples of both tumours were then postfixed for 1 hour in $2 \%$ Millonig's buffered $\mathrm{OsO}_{4}$, dehydrated in a graded series of ethanols, and embedded in styrene-methacrylate as described by Stockem and Komnick. ${ }^{16}$ Thin sections were cut on a LKB ultratome III and placed on Pioloform F coated copper grids. ${ }^{17}$ After staining with uranyl acetate and lead citrate, sections were examined with a Philips 300 electron microscope at an accelerating voltage of $80 \mathrm{kV}$.

\section{MYOSIN PREPARATIONS}

Normal adult rabbit muscles as controls were taken from the thigh of healthy animals. For comparative purposes, fetal muscles were taken from 3-month-old human fetuses. Normal, fetal, and tumoral muscles were fragmented in a Waring-Blender homogeniser for 2 minutes at high speed. The myosins were extracted with a modified Hasselbach-Schneider solution at high ionic strength and in the presence of $40 \mathrm{mM} \mathrm{K} \mathrm{K}_{2} \mathrm{O}_{7}{ }^{18}$ They were then purified by suspension-reprecipitation cycles ${ }^{19}$ and by ammonium sulphate fractionation using the 40 to $50 \%$ saturated ammonium sulphate fraction. ${ }^{20}$ All details were described in a previous investigation. ${ }^{15}$

Protein concentrations were determined by the biuret method as well as with the molar extinction coefficient $E_{1 \%}^{280}=5 \cdot 60$. The latter values were compared with those obtained by the biuret method and found to be accurate when the $A_{280 n m} / A_{260 n m}$ ratio was 1.40 or greater.

Reprecipitated or synthetic filaments were obtained by rapid dilution from $500 \mathrm{mM} \mathrm{KCl}, 10 \mathrm{~mm}$ $\mathrm{MgCl}_{2}, \mathrm{pH} 6 \cdot 8$, to $100 \mathrm{~mm} \mathrm{KCl}, 10 \mathrm{~mm} \mathrm{MgCl}_{2}$, pH 6.8, and examined in a Philips 300 electron microscope after negative staining with uranyl acetate. ${ }^{21}$

Sodium dodecyl sulphate (SDS)-polyacrylamide gel electrophoresis using Laemmli's ${ }^{22}$ buffer system and Kerckaert's apparatus ${ }^{23}$ was performed on 10 to $25 \%$ acrylamide gradient slab gel $(15 \times 10 \times 0.1$ cm).
The conditions for $\mathrm{Ca}^{2+}$ ATPase activity measurements were those described previously. ${ }^{15}$

\section{Results}

\section{MORPHOLOGY OF PRIMARY TUMOUR}

Histologically, the neoplasm displayed mesenchymatous features. Most of the tumour was composed of undifferentiated spindle-celled elements (Fig. 1), the character of which could not be determined: possibly fibroblastic cells, tumour cells of smooth muscle origin, transformed Schwann cells, or elongated rhabdomyoblasts. After exhaustive examination of histological sections, different regions were found which indicated a rhabdomyosarcomatous origin. There were areas with an appearance of undifferentiated embryonic rhabdomyosarcoma and others of the botryoïd type (Fig. 2). The low frequency of rhabdomyoblasts was confirmed by electron microscopy, where only few cells with myofibrillar differentiation were found (Fig. 3).

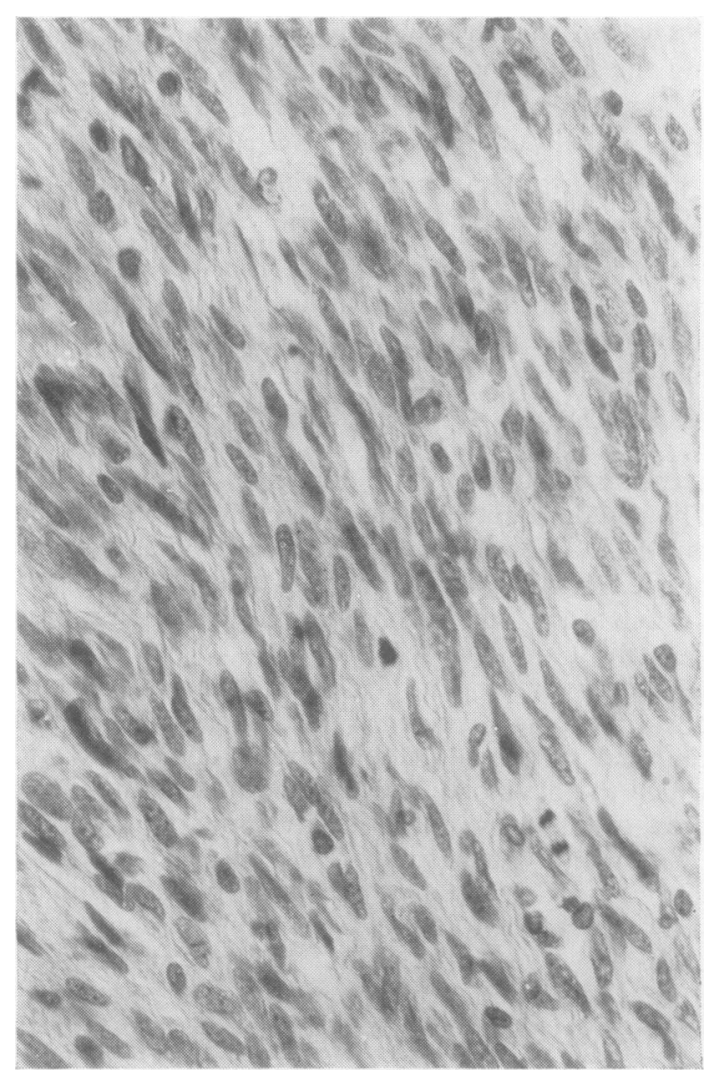

Fig. 1 General histological appearance of the primary tumour. $90 \%$ of the examined surface displays undifferentiated spindle-like cells. Haematoxylin and eosin $\times 200$. 


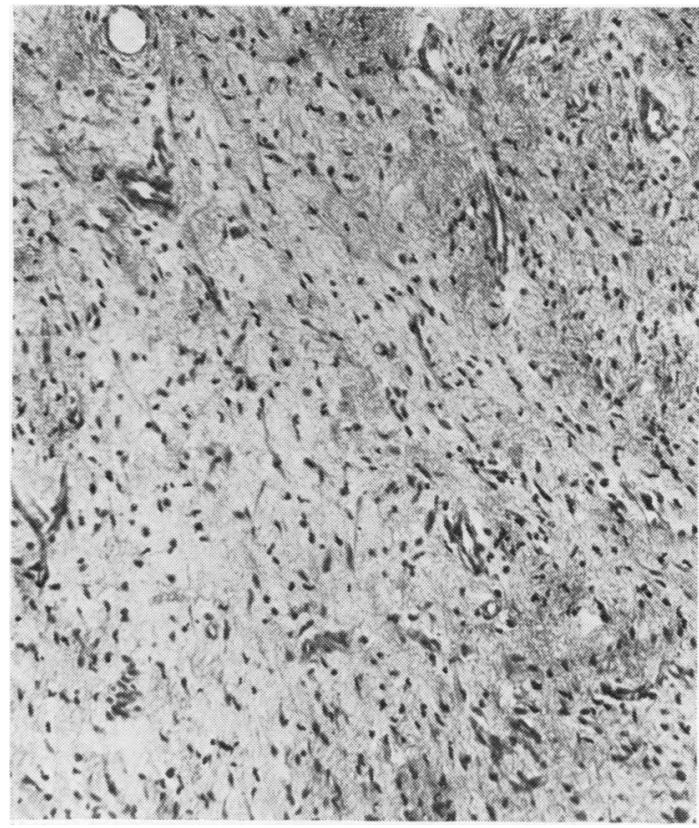

Fig. 2 Botryoid type region of embryonic rhabdomyosarcoma in the primary tumour. $H$ and $E \times 100$.
MORPHOLOGY OF RECURRENT TUMOUR

The same histological features occurred in the recurrent tumour but in different proportions. Botryoïd areas of embryonic rhabdomyosarcoma were particularly developed at the periphery of the tumour; in the centre, the undifferentiated type, characterized by the presence of long fusiform cells (Masson's myocytes) and large polymorphic cells (Masson's myoblasts) (Fig. 4), was prominent. The latter cells displayed a fibrillar network in their cytoplasm.

Electron microscopy revealed the existence of myofibrillar structures in practically all the cells. The most differentiated stage that could be observed showed only myofilament alignment in the form of myofibrils without precise orientation. Z-lines were very hypərtrophied. Sarcomeres were very irregular and generally found to be in a supercontracted state. M-lines were not observed. Large quantities of glycogen were present, especially in the vicinity of Z-lines. The nuclei often contained nuclear bodies of fibrillar and/or granular structure. An electron dense, amorphous material was frequently observed in the sarcoplasmic reticulum.

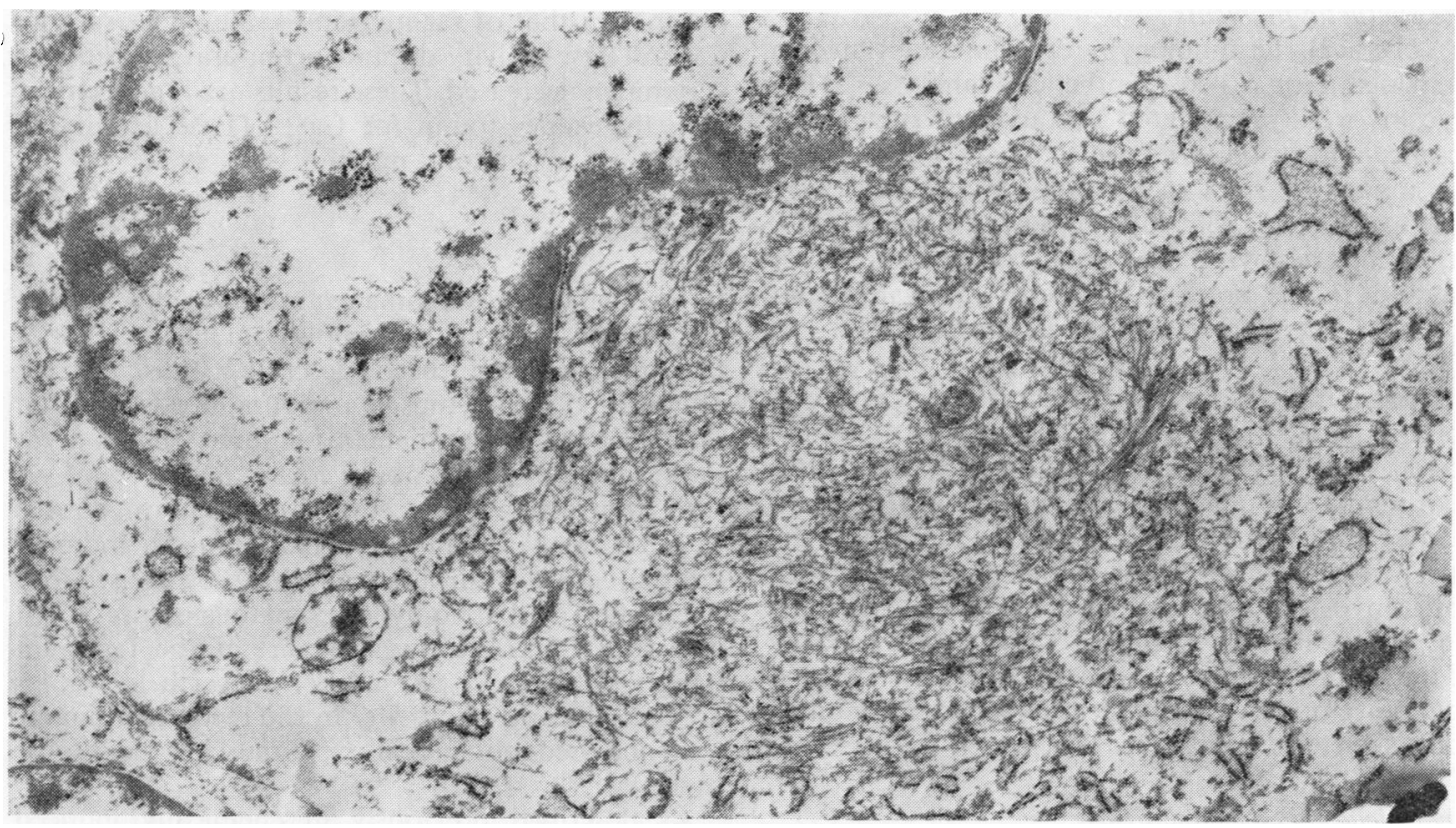

Fig. 3 Rare rhabdomyoblast of the primary tumour with myofibrillar differentiation. Myofilaments have no precise orientation. $\times 13700$. 


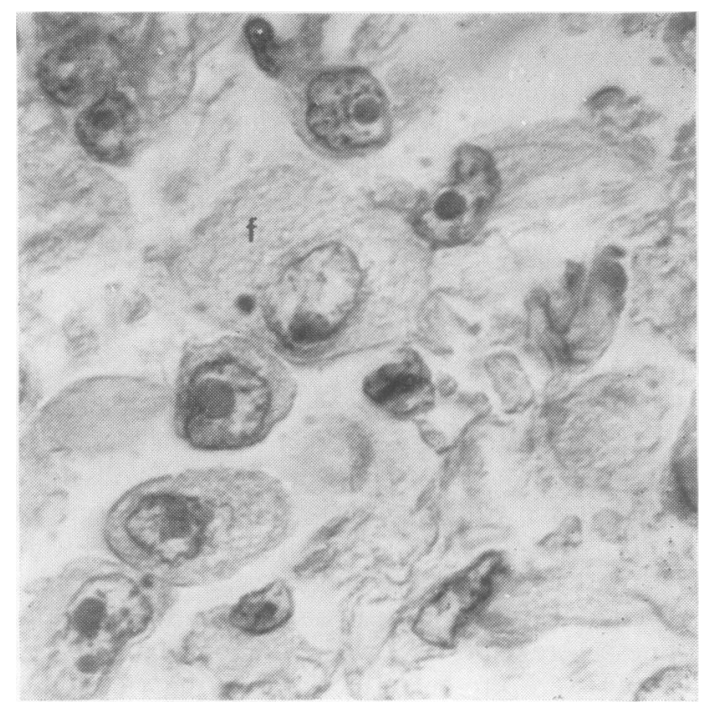

Fig. 4 Immature rhabdomyoblasts of the recurrent tumour. Note the presence of fibrillar structures in some cells $(f)$. The nuclei display very large nucleoli. (Masson's trichrome) $\times 800$.

TUMORAL AND FETAL MYOSINS

Tumoral myosin was extracted from $80 \mathrm{~g}$ of the recurrent tumour. Fetal myosin was isolated from $60 \mathrm{~g}$ fresh human fetal muscle.

\section{The synthetic filcments}

In classical terminology, reprecipitated myosin filaments are called synthetic filaments. ${ }^{24}$ The myosins were precipitated by rapid dilution in the absence and in the presence of $10 \mathrm{~mm} \mathrm{MgCl}$. The two myosins formed in the absence of $\mathrm{MgCl}_{2}$ were seen to be exclusively short bipolar filaments (Fig. $5 \mathrm{a}, \mathrm{b})$ such as myosin of normal skeletal muscle of rat and rabbit precipitated under the same conditions. ${ }^{24}$ The filaments varied in length from 0.3 to $0.6 \mu \mathrm{m}$.

The width was about $15 \mathrm{~nm}$ at the bare zone and approximately $50 \mathrm{~nm}$ at the extremities. In the presence of $\mathrm{MgCl}_{2}$, however, the tumoral and fetal myosins precipitated essentially as long fusiform filaments with an average width of $25 \mathrm{~nm}$ (Fig. 5c, d) The length of the filaments was quite variable for both myosins. The smallest filaments measured $0.6 \mu \mathrm{m}$, the longest $10 \mu \mathrm{m}$ or greater. The majority of the filaments did not exceed $2 \mu \mathrm{m}$. There was no possibility of isolating myosin from normal human adult skeletal muscle.

\section{Analytical gel electrophoresis}

The tumoral and fetal human myosins were analysed by SDS-gel electrophoresis and compared with rabbit white skeletal muscle myosin.

In the gel of rabbit myosin (Fig. 6a), myosin heavy chains, M-proteins, C-protein, actin, the three light chains of 25000,18000 , and 16000 daltons, and troponin-T, tropomyosin, and troponin-I as contaminants could be recognised. The human tumoral myosin (Fig. 6b) as well as the human fetal myosin (Fig. 6c) contained only two light chains. Other proteins, such as $\beta$-actinine and troponin $\mathrm{C}$, could be observed in these gels. The 27000 daltons protein of human tumoral myosin and the 17000 daltons protein of human fetal myosin could not be identified.

Futhermore, the gel of tumoral human myosin (Fig. 6b) revealed various proteins, the molecular size of which was found to be between 140000 and 45000 daltons and between 34000 and 25000 daltons. These proteins were probably polypeptic fragments of the heavy chains. Indeed, many proteolytic enzymes are known to exist in tumours.

\section{$\mathrm{Ca}^{2+}$ ATPase activity}

Measurements of the specific $\mathrm{Ca}^{2+} \mathrm{ATPase}$ activity of the two different human myosins were performed and the results compared with the specific $\mathrm{Ca}^{2+}$ ATPase activity of rabbit white muscle myosin and of rat red muscle myosin. The comparison with rat red muscle myosin seemed to be necessary as human muscle is also a red muscle. Human fetal myosin has a specific activity of $\mathrm{Ca}^{2+}$ ATPase somewhat lower than that of rat myosin (Table). The specific $\mathrm{Ca}^{2+}$ ATPase activity of human tumoral myosin was very much decreased. These results are in agreement with the values found for $\mathrm{Ca}^{2+}$ ATPase activity of rabbit and rat tumoral myosins. ${ }^{14} 15$

\section{Discussion}

In the rhabdomyosarcoma examined in this investigation, the essential morphological characteristics that have already been described thus far for chemically induced muscle tumours in rats ${ }^{25-28}$ and rabbits $^{29}$ or for spontaneous human rhabdomyosarcomas ${ }^{30}$ have been observed.

In contrast to the recurrent tumour, myofibrils were extremely rare in the primary tumour, and only a careful examination of many histological sections established its rhabdomyosarcomatous nature. Light microscopy and the ultrastructure of the recurrent tumour confirmed its nature. Nevertheless it is difficult to understand why in the recurrent tumour only one predominant cell type, muscle cells, can be observed.

As described previously in chemically induced rhabdomyosarcomas, irregularly arranged myofibrils with supercontracted sarcomeres were obser- 


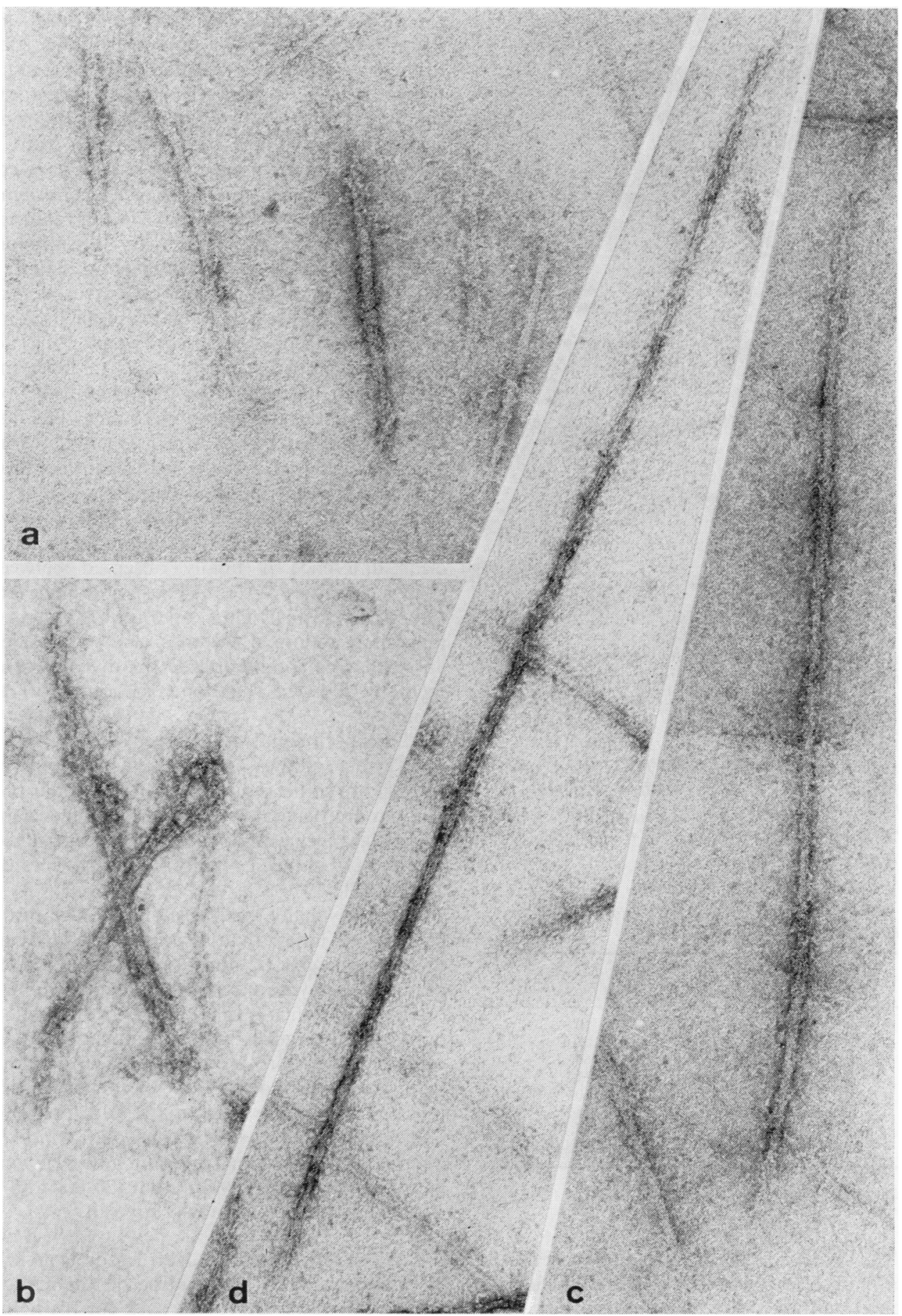

Fig. 5 Synthetic filaments of human fetal and tumoral myosins (negative staining). In the absence of $\mathrm{MgCl}_{2}$, fetal (a) and tumoral (b) myosins form bipolar filaments. When $\mathrm{MgCl}_{2}$ is added, fetal (c) as well as tumoral (d) myosins precipitate as long fusiform filaments. All micrographs: original magnification $\times 120000$. 


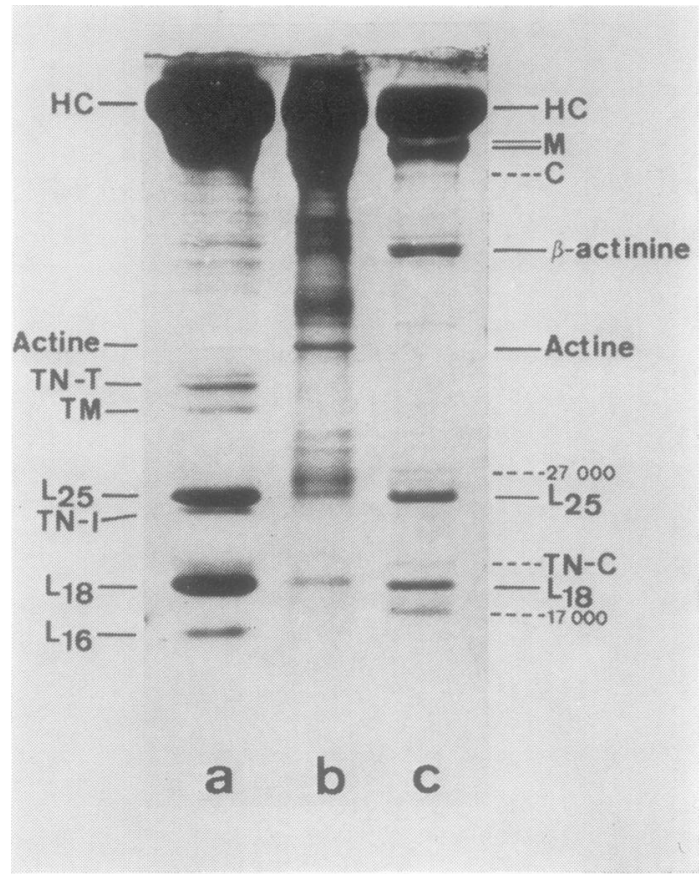

Fig. 6 SDS-polyacrylamide gel electrophoresis of normal rabbit (a), human tumoral $(b)$, and human fetal (c) myosins. Note absence of 16000 daltons light chain in human fetal and tumoral myosins. $\mathrm{HC}=$ heavy chains; $M=M$-protein; $C=C$-protein; $T N-T=$ tropomyosin binding troponin factor; $T N-C=$ calcium binding troponin factor; $T N-I=$ inhibitory troponin factor; $T M=$ tropomyosin; $L_{25}, L_{18}, L_{16}=$ light chains with a molecular size of 25000,18000 , and 16000 daltons respectively.

Maximal values of $\mathrm{Ca}^{2+}$ ATPase activity of different normal, fetal, and tumoral myosins

\begin{tabular}{llc}
\hline Material & Myosins & $\begin{array}{c}\text { Maximal values } \\
(\text { nmol Pi/mg/min })\end{array}$ \\
\hline Human & Fetal & $414 \pm 10$ \\
Rat* & Tumoral & $90 \pm 8$ \\
& Normal & $450 \pm 60$ \\
Rabbit* & Fetal & $470 \pm 21$ \\
& Tumoral & $60 \pm 10$ \\
& Normal & $546 \pm 48$ \\
& Fetal & $510 \pm 35$ \\
& Tumoral & $30 \pm 10$ \\
\hline
\end{tabular}

* From Hildebrand et al. ${ }^{14}$

$\mathrm{Pi}=$ inorganic phosphorus.

ved. ${ }^{28} 29$ The absence of the M-line, necessary for the maintenance of the sarcomere, ${ }^{31}$ revealed a deficiency of M-protein synthesis. The function of the granular precipitate in the sarcoplasmic reticulum was not clear. The precipitate was believed to bea calcium carbonate or phosphate salt and has been observed in other rhabdomyosarcomas ${ }^{28}$ as well as in $\mathrm{Ni}_{3} \mathrm{~S}_{2}$-induced leiomyosarcomas. ${ }^{32}$ The presence of this substance in the cisternae may be related to a defect in calcium transport which prevents normal muscle contractile function. It is noteworthy that Gilman ${ }^{11}$ has demonstrated that myoblasts grown in vitro from nickelinduced rhabdomyosarcoma fail to achieve contractility. The role of calcium in triggering or potentiating normal and neoplastic cell division in relation to an alternative role in neuromyal transmission and contraction was shown previously by Balk. ${ }^{33}$

Human fetal and tumoral myosins can be compared with those of fetuses and $\mathrm{Ni}_{3} \mathrm{~S}_{2}$-induced rhabdomyosarcomas of rat and rabbit. ${ }^{1415}$ The same synthetic filaments are observed in both myosins precipitated as short bipolar filaments without $\mathrm{MgCl}_{2}$ in the precipitating buffer but as long fusiform filaments when $\mathbf{M g C l}_{2}$ is added. Moreover, analogies are found in the light-chain composition: the two myosins possess two light chains with a molecular size of 25000 and 18000 daltons, whereas normal muscle myosin has three light chains. A clear difference is finally observed between the specific activities of $\mathrm{Ca}^{2+}$ ATPase of human fetal and tumoral myosins. Thus myosin of human spontaneous rhabdomyosarcomas can be considered as an isoenzyme comparable to the myosins of experimentally induced rhabdomyosarcomas of rat and rabbit.

The experimental model seems to be convenient for further studies in molecular biology on the control of synthesis of tumoral myofibrillar proteins. On a more general level, one can believe that the molecular mechanisms occurring in spontaneous or chemically induced tumoral transformation are comparable.

It is noteworthy that these biochemical results can be obtained in less than three days, and they may be useful for diagnostic purposes, especially in embryonic rhabdomyosarcomas, the diagnosis of which is often rather difficult. In addition, the method may be used to distinguish undifferentiated rhabdomyosarcomas from fibrosarcomas because of the different light chain composition of the myosins of these tumours: rhabdomyosarcoma myosin possesses two light chains of skeletal myosin (25000 and 18000 daltons); fibrosarcoma myosin, however, has two light chains completely different (20 000 and 15000 daltons) similar to fibroblast myosin. ${ }^{12}$

We are deeply indebted to Professor Dr A Clay for his interest and critical reading of this manuscript, and to Professor Dr R Marusyk for his help in its revision. We thank Miss $M$ Soltysiak and Mrs S Quief for skilful technical assistance, and Mrs M-T Garet for expert photographic work. 
This work was supported by grants from the Institut National de la Santé et de la Recherche Médicale (INSERM U 124 and ATP 38.76.70) and the Centre National de la Recherche Scientifique (LA No. 04 268).

\section{References}

${ }^{1}$ Dito WR, Batsakis JG. Rhabdomyosarcoma of the head and neck. Arch Surg 1962;84:582-8.

2 Mahour GH, Soule FH, Mills SD, Lynn HB. Rhabdomyosarcoma in infants and children: a clinicopathologic study of 75 cases. J Pediat Surg 1967;2:402-9.

${ }^{3}$ Enzinger FM, Shiraki M. Alveolar rhabdomyosarcoma: an analysis of 110 cases. Cancer 1969;24:18-31.

${ }^{4}$ Sinkovics JG, Shirato E, Cabiness JR, Martin RG. Rhabdomyosarcoma after puberty. Clinical, tissue culture and immunological studies. J Med (Basel) 1970; 1:313-26.

${ }^{5}$ Sutow WW, Sullivan MP, Ried HL, Taylor HG, Griffith KM. Prognosis in childhood rhabdomyosarcoma. Cancer 1970;25:1384-90.

- Donaldson SS, Castro JR, Wilbur JR, Jesse RH, Jr. Rhabdomyosarcoma of head and neck in children. Combination, treatment by surgery, irradiation, and chemotherapy. Cancer 1973;31:26-35.

7 Bale PM, Reye RDK. Rhabdomyosarcoma in childhood. Pathology 1975;7:101-11.

${ }^{8}$ Liebner EJ. Embryonal rhabdomyosarcoma of head and neck in children. Correlation of stage, radiation dose, local control, and survival. Cancer 1976;37:2777-86.

- Weichert KA, Bove KC, Aron BS, Lampkin B. Rhabdomyosarcoma in children. A clinico-pathological study of 35 patients. Amer J Clin Pathol 1976;66:692-701.

${ }^{10}$ Raney RB, Hays DM, Lawrence W, Jr, Soule EH, Tefft M, Donaldson MH. Paratesticular rhabdomyosarcoma in childhood. Cancer 1978;42:729-36.

11 Gilman JPW. Muscle tumorigenesis. In: Canadian Cancer Conference: Proceedings of the VIth Canadian Research Conference, Honey Harbour, Ontario. New York: Pergamon Press, 1965;209-23.

12 Adelstein RS, Conti MA. The effect of phosphorylation on platelet myosin and studies on substrates for platelet myosin light-chain kinase. In: Goldman $\mathrm{R}$, Pollard $\mathrm{T}$, Rosenbaum J, eds. Cell Motility-Book B-Actin, Myosin and Associated Proteins. (Cold Spring Harbor Conferences on Cell Proliferation, Vol. 3). Cold Spring Harbor, NY: Cold Spring Harbor Laboratory, 1976;725-38.

${ }^{13}$ Gabbiani G, Csank-Brassert J, Schneeberger JC, Kapanci Y, Trenchev P, Holborow EJ. Contractile proteins in human cancer cells. Immunofluorescent and electron microscopic study. Amer J Pathol 1976;83:457-74.

14 Hildebrand HF, Kerckaert JP, Biserte G, Grandier-Vazeille $X$, Tetaert D. Myosin of $\mathrm{Ni}_{3} \mathrm{~S}_{2}$-induced rhabdomyosarcomas: A new onco-fetal isoenzyme. In: Lehmann FG, ed. Carcino-embryonic Proteins, Vol. 2. Amsterdam: Elsevier/North-Holland Biomedical Press B.V, 1979; 717-22.

${ }^{15}$ Hildebrand HF, Kerckaert JP, Biserte G, Tetaert D, Grandier-Vazeille X. Tumoral myosins of $\mathrm{Ni}_{3} \mathrm{~S}_{2}$-induced rhabdomyosarcomas in rat and rabbit: comparative studies with adult and fetal myosins of skeletal muscle. Eur J Cell Biol 1980;20:240-8.
${ }^{18}$ Stockem W, Komnick H. Erfahrungen mit der StyrolMethacrylat-Einbettung als Routine-methode für die Licht- und Elektronenmikroskopie. Mikroskopie 1970; 26:199-203.

${ }^{17}$ Stockem W. Die Eigung von Pioloform F für die Herstellung elektronenmikroskopischer Trägerfilme. Mikroskopie 1970;26:185-9.

18 Tetaert D, Moreau O, Han KK, Hildebrand HF, Biserte G. Isolement et caractérisation de la chaîne légère $\mathrm{L}_{17}$ de la myosine de muscle lisse d'utérus de vache. Biochimie 1977;59:337-9.

19 Perry SV. Myosin adenosinetriphosphatase. In: Colowick SP, Kaplan NO, eds. Methods in Enzymology, Vol. 2. New York: Academic Press, 1955;582-8.

${ }^{20}$ Offer G, Moos C, Starr RL. A new protein of the thick filaments of vertebrate skeletal myofibrils. Extractions, purification, characterization. J Mol Biol 1973;74: 653-76.

${ }^{21}$ Oriol C, Landon MF, Hildebrand HF. Physico-chemical studies of Straub- and KI-Actin. Cytobiologie 1977; 14:350-61.

${ }^{22}$ Laemmli UK. Cleavage of structural proteins during the assembly of the head of bacteriophage T4. Nature (Lond) 1970;227:680-5.

${ }^{23}$ Kerckaert JP. Highly simplified analytical or preparative slab gel electrophoresis. Anal Biochem 1978;84:354-60.

${ }^{24}$ Huxley HE. Electron microscope studies on the structure of natural and synthetic protein filaments from striated muscle. J Mol Biol 1963;7:281-308.

${ }^{25}$ Basrur PK, Sykes AK, Gilman JPW. Changes in mitochondrial ultrastructure in nickel sulfide induced rhabdomyosarcoma. Cancer 1970;25:1142-52.

${ }^{26}$ Bruni C, Rust JN. Fine structure of dividing cells and of nondividing differentiating cells of nickel-sulfide induced rhabdomyosarcomas. J Nat Cancer Inst 1975;54:687-96.

27 Friedmann I, Bird ES. Electron-microscope investigation of experimental rhabdomyosarcoma. J Pathol 1969; 97:375-82.

${ }^{28}$ Hildebrand HF, Biserte G. Ultrastructural investigation of $\mathrm{Ni}_{3} \mathrm{~S}_{2}$-induced rhabdomyosarcoma in Wistar rat. Comparative study with emphasis on myofibrillar differentiation and ciliar formation. Cancer 1978;42: $528: 54$.

${ }^{29}$ Hildebrand HF, Biserte G. Cylindrical laminated bodies in nickel-subsulphide-induced rhabdomyosarcoma in rabbits. Eur J Cell Biol 1979;19:276-80.

${ }^{30}$ Sarkar K, Tolnai G, McKay DE. Embryonal rhabdomyosarcoma of the prostate. An ultrastructural study. Cancer $1973 ; 31: 442-8$.

${ }^{31}$ Knappeis GG, Carlsen F. The ultrastructure of the $M$ line in skeletal muscle. $J$ Cell Biol 1968;38:202-11.

${ }^{32}$ Hildebrand HF, Biserte G. Nickel sub-sulphide-induced leiomyosarcoma in rabbit white skeletal muscle. A light microscopical and ultrastructural study. Cancer 1979; 43:1358-74.

${ }^{33}$ Balk SD. Calcium as regulator of the proliferation of normal, but not of transformed, chicken fibroblasts in a plasma-containing medium. Proc Natl Acad Sci USA $1971 ; 68: 271-5$.

Requests for reprints to: Dr Hartmut Hildebrand, Institut de Recherches sur le Cancer et Unité 124 de l'INSERM, BP 3567, F-59020 Lille Cédex, France. 